\title{
Métodos de seleção granulométrica com foco na resistência à deformação permanente
}

\author{
Jorge Luis Santos Ferreira ${ }^{1}$, Jorge Barbosa Soares ${ }^{2}$ e Juceline Batista dos Santos Bastos ${ }^{3}$
}

\begin{abstract}
Resumo: A granulometria de uma mistura asfáltica tem papel relevante em sua resistência à deformação permanente. Neste trabalho, avalia-se e compara-se os métodos Bailey e Faixa de Agregados Dominantes (FAD). Ambos buscam fornecer granulometrias com intertravamento adequado para resistir à deformação permanente. Utilizou-se 8 misturas asfálticas produzidas com materiais de diferentes regiões do Brasil. Os resultados mostram que o método FAD pode ser utilizado em fase de projeto para estimar o desempenho de campo das misturas asfálticas quanto à resistência à deformação permanente baseandose em um único parâmetro granulométrico (porosidade FAD). Por outro lado, dos parâmetros do método Bailey (AG, GAM e FAM), apenas os valores de AG refletem o comportamento mecânico das misturas asfálticas. Os resultados de laboratório e de campo indicam o potencial para aplicação prática do método FAD.
\end{abstract}

Palavras-chave: deformação permanente, Flow Number, seleção granulométrica, método FAD e Bailey.

Abstract: Aggregate gradation of an asphalt mixture has an important role in its resistance to permanent deformation. In this paper, the Bailey method and the Dominant Aggregate Size Range (DASR) model are evaluated and compared. Both methodologies intend to select aggregate gradation with proper interlocking to resist permanent deformation. Eight asphalt mixtures produced with materials from different regions in Brazil were used. The results show that the DASR model can be used in mixture design to estimate field performance of asphalt mixtures with respect to permanent deformation based on a single parameter, the DASR porosity. On the other hand, among the parameters of the Bailey method (AG, GAM and FAM), only the AG values reflect the mechanical behavior of asphalt mixtures. The laboratory and field results indicate that the DASR model has potential for practical application.

Keywords: permanent deformation, Flow Number, gradation selection, DASR model and Bailey method.

\section{INTRODUÇÃO}

O afundamento de trilha de roda em pavimentos corresponde ao acúmulo permanente de deformação ao longo do tempo decorrente do carregamento repetido do tráfego. Trata-se de um dos principais defeitos dos pavimentos que utilizam revestimentos asfálticos, e seu surgimento se dá tipicamente nas idades iniciais. Segundo White et al. (2002), a deformação excessiva do revestimento origina a maioria das falhas de deformação permanente do pavimento, embora todas as camadas possam contribuir para esse defeito.

Ahlrich (1996) afirma que a deformação permanente é controlada principalmente pelos agregados e pelo método de dosagem da mistura asfáltica, destacando como uma das causas a granulometria inadequada. Para Stakston e Bahia (2003), a angularidade e a granulometria têm um papel maior na falha em questão. Galalipour et al. (2012) concluíram que o intertravamento entre as partículas, assim como o ângulo de fricção, desempenham um papel crítico na resistência à deformação permanente, pois influenciam a formação de um esqueleto resistente. Portanto, a literatura mostra que as características dos agregados numa mistura asfáltica, sobretudo sua granulometria, afetam de maneira

\footnotetext{
1 Jorge Luis Santos Ferreira, Departamento de Engenharia de Transportes, UFC. (jorge.eng.luis@hotmail.com)

2 Jorge Barbosa Soares, Departamento de Engenharia de Transportes, UFC. (jsoares@det.ufc.br)

3 Juceline Batista dos Santos Bastos, Departamento de Engenharia de

Transportes, UFC. (jucelinebatista@hotmail.com)
}

Manuscrito recebido em 16/04/2016 e aprovado para publicação em 07/07/2016.

Este artigo é parte de TRANSPORTES v. 24, n. 2, 2016. ISSN: 2237-1346 (online). DOI:10.4237/transportes.v24i2.1129 significativa seu desempenho na resistência à deformação permanente.

Embora não seja a única causa, a escolha de uma granulometria inadequada tende a favorecer o desenvolvimento precoce de deformação permanente. Tal defeito também implica diretamente na segurança do usuário, pois resulta acúmulo d'água, aquaplanagem, atrito e dificuldade para manobrar o veículo. Na seleção das granulometrias, as especificações técnicas definem intervalos que devem ser obedecidos pelos percentuais passantes em cada peneira. Esse tipo de metodologia é adotado tanto em nível nacional (e.g., faixas do DNIT) quanto internacionalmente (e.g., pontos de controle da AASHTO). Porém, o impacto das granulometrias escolhidas no comportamento mecânico das misturas asfálticas não é estimado. Uma consequência imediata disso é a possibilidade de composição de misturas com um esqueleto pétreo sem estabilidade e com intertravamento inadequado, portanto, com reduzida resistência à deformação permanente.

Dessa forma, faz-se necessária a adoção de um método racional que possa dar subsídio à escolha da composição granulométrica mais adequada. O presente artigo avalia e compara os métodos Bailey e Faixa de Agregados Dominantes. O método Bailey foi desenvolvido pelo engenheiro americano Robert Bailey na década de 1980 e é apresentado em sua formulação atual por Vavrik (2000). O método de Faixa de Agregados Dominantes, originalmente chamado Dominant Aggregate Size Range (DASR) model, foi proposto por Kim (2006) e constitui-se em uma alternativa ao método Bailey. Ambos os métodos fundamentam-se na teoria do empacotamento de partículas e propõem abordagens relativamente distintas para especificar e avaliar a estrutura granulométrica de misturas asfálticas. 
Tabela 1. Peneiras de controle do método Bailey

\begin{tabular}{lcccccc}
\hline Tamanho Máximo Nominal (TMN) (mm) & 37,5 & 25 & 19 & 12,5 & 9,5 & 4,75 \\
Peneira Média (PM) (mm) & 19 & 12,5 & 9,5 & 6,25 & 4,75 & 2,36 \\
Peneira de Controle Primário (PCP) (mm) & 9,5 & 4,75 & 4,75 & 2,36 & 2,36 & 1,18 \\
Peneira de Controle Secundário (PCS) (mm) & 2,36 & 1,18 & 1,18 & 0,6 & 0,6 & 0,3 \\
Peneira de Controle Terciário (PCT) (mm) & 0,6 & 0,3 & 0,3 & 0,15 & 0,15 & 0,075 \\
\hline
\end{tabular}

\section{REVISÃO DE LITERATURA}

\subsection{Método Bailey}

Segundo Vavrik (2000), o método Bailey objetiva determinar a melhor composição granulométrica para uma dada mistura asfáltica levando em consideração os requisitos volumétricos de dosagem e obtendo características adequadas de compactação. Esse método fornece um melhor entendimento de como se relacionam a granulometria e os vazios da mistura asfáltica (Vavrik et al., 2002). A quantidade de vazios numa mistura asfáltica pode ser ajustada considerando o percentual de cada material. Pode-se identificar alguns princípios básicos usados na aplicação do método. O primeiro deles é a definição das frações graúda e miúda. A separação entre a fração graúda e a miúda é definida pela Peneira de Controle Primário (PCP) em função do Tamanho Máximo Nominal (TMN) da composição granulométrica. A PCP é estimada como a abertura da peneira mais próxima a $0,22 \times$ TMN. Os outros princípios são: análise da fração graúda, avaliação da fração graúda do agregado miúdo e análise da fração miúda do agregado miúdo. Para isso, outras peneiras também são definidas: Peneira de Controle Secundário (PCS), Peneira de Controle Terciário (PCT) e Peneira Média (PM). A Tabela 1 apresenta essas peneiras de controle em função do TMN.

A PCP é utilizada para classificar a composição granulométrica escolhida em graúda ou miúda a partir do percentual retido nessa peneira, a qual varia em função do TMN de cada mistura conforme apresentado na AASHTO M 323 (2013). O material passante na PCP e retido na PCS é denominado como a fração graúda do agregado miúdo. Já o material passante na PCS é denominado como a fração miúda do agregado miúdo, a qual é avaliada pela PCT. A PM é utilizada para avaliação do agregado graúdo. A seleção de uma granulometria parte da Massa Específica Escolhida (MEE), que para misturas graúdas e finas corresponde a um percentual da Massa Específica Solta (MES). Essa última é definida como a quantidade de agregado que preenche determinado volume sem ser aplicado nenhum esforço de compactação. Também define-se a Massa Específica Compactada (MEC), que é a quantidade de agregado que preenche um determinado volume com a aplicação de um esforço de compactação específico (Vavrik et al., 2002). Há três parâmetros de proporção necessários para a análise da estrutura granulométrica, os quais permitem a verificação de algumas características da mistura asfáltica. A proporção de Agregados Graúdos (AG) está relacionada à trabalhabilidade e à propensão à segregação da mistura asfáltica. A quantidade de material fino e a estabilidade estão associadas à proporção Graúda do Agregado Miúdo (GAM). Já a proporção Fina do Agregado Miúdo (FAM) influencia no VAM das misturas asfálticas. Os intervalos recomendados para esses parâmetros em misturas asfálticas tanto com granulometria de comportamento graúdo quanto miúdo são apresentadas em Vavrik et al. (2002). Esses autores também definem as novas peneiras de controle para as misturas asfálticas finas. Exemplos numéricos com um passo-a-passo detalhado da escolha e avaliação de granulometrias de acordo com o método Bailey são apresentados por Vavrik et al. (2002). Seu desenvolvimento completo pode ser encontrado em Vavrik (2000).

\subsection{Método de Faixa de Agregados Dominantes (FAD)}

O método de Faixa de Agregados Dominantes (FAD) permite avaliar a estrutura granulométrica de misturas asfálticas objetivando a composição de um esqueleto pétreo que confira estabilidade e resistência à deformação permanente. Essa resistência é garantida por um contato adequado entre partículas suficientemente graúdas. Kim (2006) estabelece que apenas as partículas iguais ou maiores que $1,18 \mathrm{~mm}$ (peneira $\mathrm{N}^{\mathrm{o}} 16$ ) contribuem efetivamente para tal resistência.

A mistura asfáltica é descrita como sendo formada pela Faixa de Agregados Dominantes (FAD) e pelo Volume Intersticial (VI). O primeiro é responsável pela resistência à deformação permanente, enquanto o segundo está ligado ao trincamento por fadiga e à energia de ruptura da mistura, além de manterem as partículas da FAD unidas, conferindo adesão e resistência à tração (Kim, 2006; Greene et al., 2014). Compõem o VI, os agregados inferiores à FAD, o ligante asfáltico e os vazios da mistura asfáltica, todos chamados de Componentes Intersticiais (CI). Destaca-se que nem todos os agregados suficientemente graúdos irão compor a FAD (Kim, 2006). Há a consideração de que partículas com dimensões superiores à FAD flutuam na matriz de agregados de modo que não havendo contato entre as mesmas não há contribuição relevante para a resistência à deformação permanente. Os conceitos do método FAD são ilustrados na Figura 1.

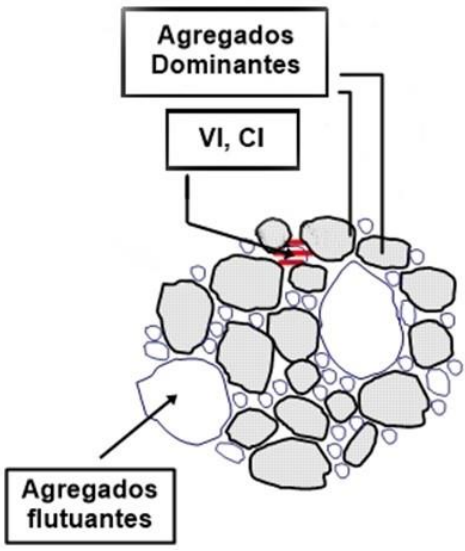

Figura 1. Mistura asfáltica segundo o método FAD (adaptada de Kim, 2006)

Kim (2006) identificou que o espaçamento médio dos agregados retidos entre quaisquer duas peneiras consecutivas aumenta rapidamente quando a proporção relativa entre elas é inferior a 0,43 ou superior a 2,33 . Isso sugere que dentro desse intervalo os agregados mantêm um espaça- 
mento relativamente constante e garantem um contato efetivo necessário para formar o esqueleto pétreo que será responsável por resistir à deformação permanente. Tais agregados são chamados de agregados dominantes e compõem a FAD da mistura asfáltica. A representação gráfica das proporções relativas entre todas as peneiras contíguas de uma mistura asfáltica é denominada diagrama de interação e permite uma visão global de todas as peneiras que estão interagindo para a formação da $\mathrm{FAD}$.

Embora a FAD seja a estrutura primária para resistir à deformação permanente, a partir da determinação de sua porosidade é que se estima seu potencial de resistência. Uma porosidade FAD inferior a $48 \%$ indica composições granulométricas com grande potencial de resistência à deformação permanente. Porosidades FAD entre 48 e 52\% são chamadas de porosidades marginais e indicam composições com contato granular questionável, não sendo possível estimar a resistência à deformação permanente. Espera-se baixa resistência à deformação permanente de misturas com porosidade FAD superior a $52 \%$.

A porosidade é uma medida adimensional definida como a proporção relativa entre o volume de vazios e volume total de determinado material. No caso da porosidade FAD de misturas asfálticas, o volume de vazios da FAD é composto pelos agregados intersticiais e pelos Vazios no Agregado Mineral (VAM), e o volume total é igual ao volume total da mistura asfáltica subtraindo-se o volume de agregados flutuantes. A Equação 1 expressa esse cálculo.

$$
\eta_{F A D}=\frac{V_{v(F A D)}}{V_{T(F A D)}}=\frac{V_{I C, a g}+V A M}{V_{T M}-V_{a g>F A D}}
$$

Onde, $\eta_{F A D}$ : porosidade FAD $(\%) ; V_{I c, a g}$ : volume de agregados intersticiais (menores do que a FAD); VA $M$ : volume de vazios no agregado mineral; $V_{T M}$ : volume total da mistura; $V_{a g>F A D}$ : volume de agregados flutuantes (maiores do que a FAD).

\section{MATERIAIS E MÉTODOS}

Para o desenvolvimento do presente trabalho foi compilado um banco de dados contemplando informações referentes a 8 misturas asfálticas densas nacionais nas faixas A, B e C do DNIT. Para todas as misturas foram levantadas suas composições granulométricas, massa específica aparente da composição de agregados, Volume de vazios (Vv) de projeto, tipo e teor de ligante, TMN, origem e abrasão Los Angeles dos agregados (DNER-ME 035, 1998), Densidade Máxima Teórica (DMT) ou Densidade Máxima Medida (Gmm) e metodologia de dosagem, dados resumidos na Tabela 2.

As misturas asfálticas (Figura 2) M1 a M3 compõem o banco de dados utilizado por Ferreira et al. (2015). A mistura M1 é uma mistura dosada pelo método Marshall e aplicada em campo em um trecho rodoviário monitorado; a mistura M2 foi obtida com os mesmos materiais e mesma granulometria da mistura M1, porém dosada pelo método Superpave; já a mistura M3 é uma variação de M2, alterando-se apenas a curva granulométrica dos agregados. As misturas M4 a M7 são laboratoriais e fazem parte das misturas estudadas por Nascimento (2008). Já a mistura M8, também laboratorial, será aplicada em um trecho experimental sob a ação de um simulador de tráfego de grande porte. Todos os agregados dessas misturas atenderam a especificação do DNIT (DNIT-ES 031, 2006) que estabelece um limite de $50 \%$ de perda por abrasão Los Angeles.

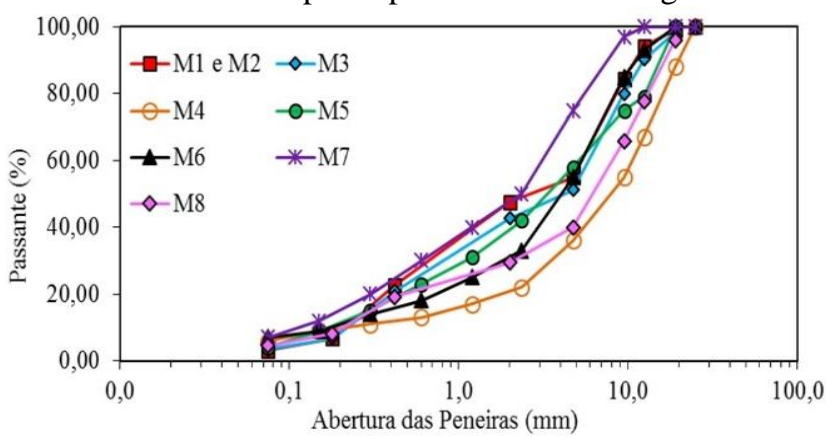

Figura 2. Curvas granulométricas das misturas asfálticas

Todas as misturas asfálticas foram submetidas ao ensaio uniaxial de carga repetida segundo o protocolo proposto por Witczak et al. (2002), obtendo-se assim seus respectivos Flow Numbers (FNs). Suas granulometrias avaliadas pelo método Bailey. A Tabela 3 resume os parâmetros Bailey e os FNs. Destaca-se que o FN está em fase de normatização no Brasil e em breve será o parâmetro de avaliação da resistência à deformação permanente para as misturas asfálticas densas nacionais.

Uma vez disponíveis os parâmetros Bailey de todas as misturas e com a subsequente determinação de suas porosidades FAD, analisou-se como cada um dos métodos avaliava o esqueleto pétreo dessas misturas em termos de resistência à deformação permanente por meio do $F N$.

Tabela 2. Características gerais das misturas asfálticas

\begin{tabular}{|c|c|c|c|c|c|c|c|c|c|}
\hline Mistura & Dosagem & $\begin{array}{c}\text { Teor de } \\
\text { CAP } \\
(\%)\end{array}$ & $\begin{array}{l}\text { TMN } \\
(\mathbf{m m})\end{array}$ & $\begin{array}{c}\text { Vvde } \\
\text { projeto } \\
(\%)\end{array}$ & $\begin{array}{l}\text { Tipo de } \\
\text { CAP }\end{array}$ & $\begin{array}{c}\text { Origem } \\
\text { agregados }\end{array}$ & $\begin{array}{c}\text { Abrasão } \\
\text { Los } \\
\text { Angeles }\end{array}$ & Gsb & $\begin{array}{c}\text { DMT } \\
\text { ou } \\
\text { Gmm }\end{array}$ \\
\hline M1 & Marshall & 5,8 & \multirow{3}{*}{12,5} & 4,2 & \multirow{3}{*}{$50 / 70$} & \multirow{3}{*}{ Gnáissica } & \multirow[t]{2}{*}{35,4} & 2,541 & 2,423 \\
\hline M2 & \multirow{2}{*}{ Superpave } & 4,3 & & 4,3 & & & & 2,541 & 2,459 \\
\hline M3 & & 4,3 & & 3,7 & & & 35,3 & 2,566 & 2,467 \\
\hline M4 & \multirow{4}{*}{ Marshall } & 4,2 & 25,0 & 4,0 & \multirow{4}{*}{ CAP 20} & \multirow{4}{*}{$\begin{array}{l}\text { Gnaisse- } \\
\text { granítica }\end{array}$} & \multirow{4}{*}{28,2} & 2,679 & 2,568 \\
\hline M5 & & 4,9 & 19,0 & 4,0 & & & & 2,672 & 2,534 \\
\hline M6 & & 4,6 & 12,5 & 4,0 & & & & 2,673 & 2,541 \\
\hline M7 & & 4,9 & 9,5 & 4,0 & & & & 2,667 & 2,523 \\
\hline M8 & Superpave & 4,5 & 19,0 & 4,0 & $50 / 70$ & Gnáissica & 35,3 & 2,643 & 2,538 \\
\hline
\end{tabular}
ligantes em questão se enquadram no tipo 50/70 dentro da atual classificação (Nascimento, 2008). 

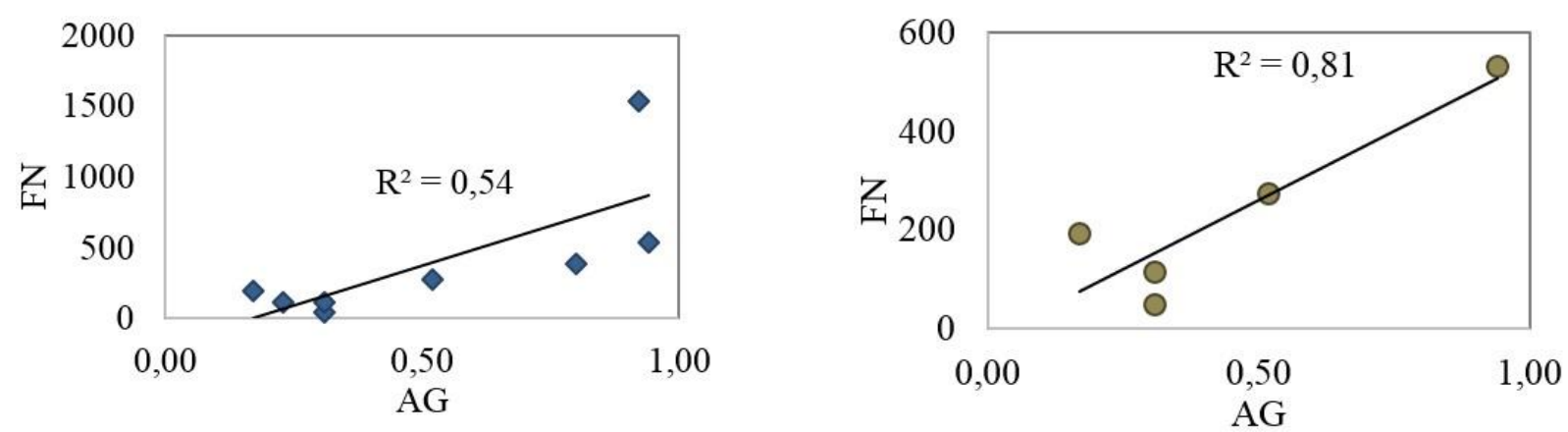

Figura 3. Correlação entre o parâmetro AG e o FN: (a) todas as misturas asfálticas e (b) excetuando-se as misturas asfálticas com porosidade FAD marginal

\section{RESULTADOS E DISCUSSÕES}

\subsection{Avaliação granulométrica das misturas asfálticas segundo o método Bailey}

A Tabela 4 apresenta os resultados dos parâmetros de proporção obtidos para todas as misturas asfálticas, assim como os intervalos recomendados por Vavrik et al. (2002) para esses parâmetros. Identifica-se que nenhuma mistura estudada atende integralmente aos valores recomendados para os parâmetros de proporção do método Bailey, sendo que cinco misturas (M3 a M7) atenderam a pelo menos um parâmetro e outras três misturas (M1, M2 e M8) não atenderam a nenhum. É constante em pesquisas nacionais $(\mathrm{Cu}-$ nha, 2004; Mendes, 2011) a dificuldade de enquadrar integralmente as granulometrias estudadas aos parâmetros Bailey.

O método Bailey determina que a estabilidade da mistura asfáltica é prejudicada quando o parâmetro de proporção AG é inferior ao limite recomendado. Adicionalmente, para alcançar as propriedades volumétricas requeridas na dosagem, há a necessidade de uma estrutura de agregado miúdo resistente.

Nesse grupo estão as misturas M1, M2, M5 e M7 (Tabela 4). Observa-se na Tabela 3 que tais misturas possuem os menores valores de $F N$, indicando suas menores resistências à deformação permanente. Esse fato pode estar associado justamente a menor estabilidade do esqueleto pétreo. Além disso, essas mesmas misturas apresentam as maiores porosidades FAD.

Por outro lado, valores de AG acima do recomendado podem representar dificuldade para a compactação em campo. Lista-se as misturas M4, M6 e M8 (Tabela 4), que conforme apresentado na Tabela 3, possuem os maiores valores de FN. Esse grupo de misturas também apresenta as menores porosidades FAD. Portanto, há indícios de que a maior resistência à deformação permanente dessas misturas, indicada por maiores valores de FN ou menores valores de porosidade FAD, pode ocasionar problemas de trabalhabilidade, indicados por maiores valores de AG. Esse resultado corrobora os resultados de Ferreira (2015) que encontrou uma forte correlação entre a porosidade FAD e o Construction Densification Index (CDI). Maiores valores de CDI (indicando maior dificuldade para compactação em campo) estão associados a menores valores de porosidade FAD (maior resistência à deformação permanente).

Apenas a mistura M3 possui um AG no intervalo recomendado. Essa mistura tem o segundo maior $F N$ sendo, portanto, uma das mais resistentes à deformação permanente entre as analisadas. Sob a ótica do método Bailey, essa mistura possui estabilidade e boa trabalhabilidade.

A Figura 3 apresenta a correlação estabelecida entre o parâmetro de proporção AG e o $F N$ das misturas asfálticas. Na Figura 3a são inclusas todas as misturas asfálticas. Conforme discutido anteriormente, todos os resultados de $F N$ são coerentes com os valores de AG. Porém a correlação gráfica possui um baixo coeficiente de determinação $\left(\mathrm{R}^{2}=\right.$ 0,54). Ao se retirar dessa correlação as misturas asfálticas com porosidade FAD marginal obtém-se uma boa correlação entre ambos os parâmetros $\left(\mathrm{R}^{2}=0,81\right)$. Ferreira (2015) já havia identificado que a inclusão das porosidades FAD marginais sempre prejudica as correlações em diversas análises. A tais porosidades estão relacionados resultados que funcionam como outliers.

Metade das misturas asfálticas (M4, M5, M6 e M7) apresentou o parâmetro GAM dentro do intervalo recomendado, porém nenhuma tendência em relação aos resultados de $F N$ foi observada. No caso do parâmetro GAM acima do limite (misturas M1, M2, M3 e M8) há a indicação do excesso de material fino. $\mathrm{O}$ método Bailey considera que isso torna a mistura asfáltica potencialmente inadequada do ponto de vista estrutural. Conforme já comentado, a mistura M1, aplicada em campo, apresenta sérios problemas de deformação permanente e a mistura M2 tem uma porosidade FAD elevada $(78,2 \%)$. Esses dois resultados vão de encontro ao que estabelece o método Bailey. Contudo, a mistura $\mathrm{M} 3$ tem $F N$ superior à M2. Essa melhor resistência à deformação permanente é esperada ao se considerar seu menor valor de porosidade FAD $(41,1 \%)$. Destaque maior deve ser dado à mistura $\mathrm{M} 8$, a qual tem porosidade $\mathrm{FAD}$ marginal $\mathrm{e}$ obteve o maior $F N$ dentre todas as misturas avaliadas, além disso, nenhum parâmetro Bailey foi atendido.

Tabela 3. Dados das misturas asfálticas

\begin{tabular}{|c|c|c|c|c|}
\hline \multirow{2}{*}{ Misturas } & \multicolumn{3}{|c|}{ Parâmetros de proporção Bailey } & \multirow[t]{2}{*}{ FN } \\
\hline & AG & GAM & FAM & \\
\hline M1 & 0,31 & 0,62 & - & 46 \\
\hline M2 & 0,31 & 0,62 & - & 112 \\
\hline M3 & 0,52 & 0,62 & - & 273 \\
\hline M4 & 0,94 & 0,47 & 0,65 & 531 \\
\hline M5 & 0,23 & 0,48 & 0,27 & 112 \\
\hline M6 & 0,80 & 0,50 & 0,50 & 384 \\
\hline M7 & 0,17 & 0,40 & - & 191 \\
\hline M8 & 0,92 & 0,63 & 0,61 & 1535 \\
\hline
\end{tabular}

O valor de FAM inferior ao limite recomendado (misturas M3 e M5) indica misturas com um valor de VAM mais elevado. De maneira oposta, as misturas M4 e M8 tendem a possuir um menor valor de VAM, pois seus valores de FAM estão acima do limite recomendado. Os valores de 
FERREIRA, J.L.S.; SOARES, J.B.; BASTOS, J.B.S.

Tabela 4. Parâmetros do método Bailey das misturas asfálticas

\begin{tabular}{ccccccc}
\hline \multirow{2}{*}{ Mistura } & \multicolumn{3}{c}{ Resultados obtidos } & \multicolumn{3}{c}{ Intervalos recomendados } \\
& AG & GAM & FAM & AG & GAM & FAM \\
\hline M1 & 0,31 & 0,62 & - & $0,60-1,00$ & $0,35-0,50$ & - \\
M2 & 0,31 & 0,62 & - & $0,60-1,00$ & $0,35-0,50$ & - \\
M3 & 0,52 & 0,62 & - & $0,50-0,65$ & $0,35-0,50$ & - \\
M4 & 0,94 & 0,47 & 0,65 & $0,70-0,85$ & $0,35-0,50$ & $0,35-0,50$ \\
M5 & 0,23 & 0,48 & 0,27 & $0,60-1,00$ & $0,35-0,50$ & $0,35-0,50$ \\
M6 & 0,80 & 0,50 & 0,50 & $0,50-0,65$ & $0,35-0,50$ & $0,35-0,50$ \\
M7 & 0,17 & 0,40 & - & $0,60-1,00$ & $0,35-0,50$ & - \\
M8 & 0,92 & 0,63 & 0,61 & $0,60-0,75$ & $0,35-0,50$ & $0,35-0,50$ \\
\hline
\end{tabular}

FAM só estavam disponíveis para cinco misturas, sendo três delas com porosidade marginal. Assim como para o parâmetro GAM, não foi possível identificar nenhuma tendência entre os valores do parâmetro FAM e o $F N$ das misturas asfálticas.

Embora cada parâmetro de proporção do método Bailey tenha sido avaliado individualmente, tal método estabelece que todos os parâmetros devem ser considerados simultaneamente no projeto do esqueleto pétreo da mistura asfáltica no intuito de garantir resistência à deformação permanente (com o adequado intertravamento) e durabilidade (com a observância dos parâmetros volumétricos de dosagem). Os resultados obtidos mostram que a resistência à deformação permanente da mistura asfáltica é influenciada, sobretudo, pelo parâmetro AG. Nascimento (2008) afirma que, ao estimar o grau de compactação da fração de agregado graúdo, o parâmetro AG torna-se o mais importante para a seleção da mistura asfáltica.

\subsection{Avaliação granulométrica das misturas asfálticas segundo o método FAD}

A partir da determinação das proporções relativas do percentual retido entre peneiras consecutivas foram construídos os diagramas de interação para cada mistura asfáltica, conforme indicado na Figura 4. O diagrama de interação permite identificar visualmente quais peneiras compõem a FAD das misturas analisadas. A FAD de cada mistura é a peneira ou grupo de peneiras que interagem entre si (possuem proporções relativas de material retido entre as proporções 2,33 e 0,43 ) e apresentam a menor porosidade.

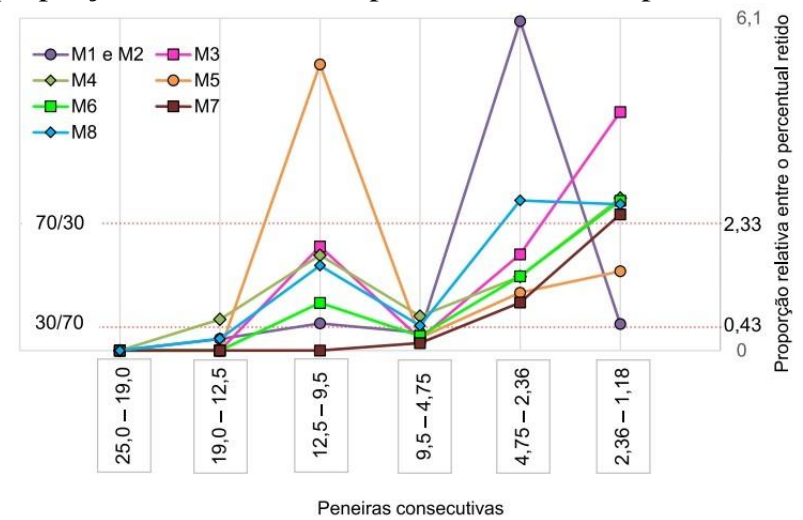

Figura 4. Diagrama de interação entre os agregados graúdos

Observa-se que para a maioria das misturas asfálticas (M1, M2, M3, M6 e M7) as interações ocorrem entre dois conjuntos de peneiras contíguas. Por exemplo, na mistura M6 há interação entre as peneiras de 12,5 e 9,5mm e entre as peneiras de 4,75 e $2,36 \mathrm{~mm}$; contudo, apenas a interação de menor porosidade é considerada na FAD. As misturas
M5 e M8 possuem interação entre três peneiras consecutivas. Já na mistura M4, há cinco peneiras consecutivas interagindo (19,0 a 2,36mm).

O cálculo da porosidade FAD para cada mistura foi realizado a partir da Equação 1, de suas curvas granulométricas e de alguns dos dados da Tabela 2 (Teor de CAP, Gsb, Vv e DMT ou Gmm). Na Tabela 5 estão identificadas as peneiras que compõem a $\mathrm{FAD}$, as respectivas porosidades e os valores de $F N$ de cada mistura.

Em relação aos resultados apresentados, destaca-se as porosidades das misturas asfálticas M5, M6 e M8, localizadas entre 48 e $52 \%$. Essas porosidades são denominadas marginais (Kim, 2006). Em tais condições os resultados dos ensaios para estimar a resistência à deformação permanente têm se mostrado bastante variáveis. Observa-se que a mistura M8 possui o maior $F N$ dentre todas as misturas asfálticas avaliadas. Por outro lado, a mistura M5 tem comportamento muito inferior conforme refletido no ensaio, semelhante à mistura M2, a qual tem uma porosidade FAD elevada.

Tabela 5. Avaliação das misturas asfálticas segundo o método FAD

\begin{tabular}{cccc}
\hline Mistura & FAD & $\begin{array}{c}\text { Porosidade } \\
\text { FAD }(\boldsymbol{\%})\end{array}$ & FN \\
\hline M1 & $2,36-1,18$ & 79,4 & 46 \\
M2 & $2,36-1,18$ & 78,2 & 112 \\
M3 & $4,75-2,36$ & 41,1 & 273 \\
M4 & $19,0-2,36$ & 31,3 & 531 \\
M5 & $4,75-1,18$ & 51,5 & 112 \\
M6 & $4,75-2,36$ & 48,0 & 384 \\
M7 & $4,75-2,36$ & 58,4 & 191 \\
M8 & $12,5-4,75$ & 48,9 & 1535 \\
\hline
\end{tabular}

Dentre as misturas asfálticas com porosidade FAD não marginal, M1 e M2 possuem as maiores porosidades FAD e os menores valores de $F N$, enquanto a mistura M4 apresentou o maior $F N$ e a menor porosidade FAD. A porosidade FAD da mistura M3 é inferior a $50 \%$ e o seu $F N$ é maior do que aqueles de todas as misturas asfálticas de porosidade FAD superior a $50 \%$. Todos esses resultados estão coerentes com aquilo que é estabelecido pelo método FAD. Destaca-se a mistura M1, a qual está nos seu primeiros anos de serviço e já apresenta deformação permanente significativa, sendo que tal comportamento pode estar associado à sua elevada porosidade FAD.

$\mathrm{Na}$ Tabela 5 é possível identificar também que embora as misturas M1 e M2 sejam constituídas pela mesma curva granulométrica, as suas porosidades FAD são um pouco diferentes. Embora a redução da porosidade FAD tenha sido pequena (1,2\%), o $F N$ aumentou em torno de 2,5 vezes, mostrando o impacto da redução do teor de ligante asfáltico na deformação permanente. Para o caso da mistura 

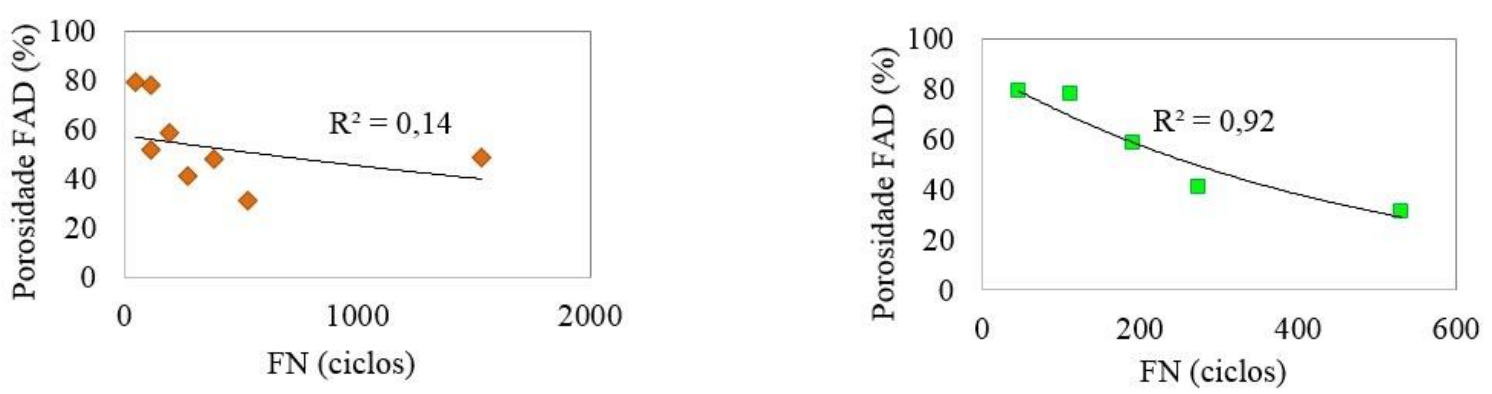

Figura 5. Correlação entre a porosidade FAD e o FN: (a) todas as porosidades FAD e (b) excetuando-se as porosidades FAD marginais

M3 (que é uma variação de M2), a alteração da granulometria conferiu uma boa redução da porosidade e um ganho no comportamento mecânico. A Figura 5a ilustra a correlação encontrada entre a porosidade FAD e o $F N$ para todas as misturas asfálticas investigadas. Já a Figura 5b apresenta a mesma correlação, contudo, sem considerar as misturas de porosidade marginal.

A baixa correlação existente entre a porosidade FAD e o $F N$ mostrada na Figura 5a já era esperada, uma vez que as porosidades marginais estão inclusas nessa análise. Por outro lado, uma forte correlação foi encontrada entre o $F N$ e as porosidades FAD localizadas fora do intervalo marginal (Figura 5b), indicando a potencialidade do método FAD como um parâmetro indicador simples da resistência à deformação permanente em misturas asfálticas.

\section{CONCLUSÕES}

$\mathrm{Na}$ busca por um método racional que subsidie a escolha da composição granulométrica mais adequada quanto à resistência à deformação permanente de misturas asfálticas, o presente artigo avaliou e comparou os métodos Bailey e Faixa de Agregados Dominantes.

Identificou-se nesta pesquisa uma forte correlação entre a porosidade $\mathrm{FAD}$ e o $F N$, mostrando o potencial do método FAD como indicador de resistência à deformação permanente. O comportamento peculiar das misturas com porosidade FAD marginal também foi confirmado, conforme havia sido identificado por Kim (2006). Apesar das simplificações adotadas pelo método FAD, seus bons resultados aliados à sua facilidade para compreensão e implementação o destacam como possível ferramenta de auxílio para um projeto de dosagem adequado de misturas asfálticas, visando reduzir sua propensão ao desenvolvimento de deformação permanente. Quando comparado ao método Bailey, o método FAD destaca-se por utilizar em suas avaliações apenas a porosidade FAD. Tal parâmetro é independente do TMN da mistura asfáltica. Para uma aplicação prática do método, a influência da redução da porosidade FAD nos aspectos de durabilidade e trabalhabilidade da mistura asfáltica devem ser incorporados.

Diferentemente do método FAD, onde todas as suas previsões de comportamento mecânico foram confirmadas para as misturas estudadas, as avaliações segundo o método Bailey não foram totalmente coerentes com aquilo que é estabelecido. Observou-se que os intervalos para seus parâmetros são difíceis de ser integralmente obedecidos, mesmo para misturas com bom resultado no ensaio uniaxial de carga repetida. Contudo, uma discussão sobre a validade desses intervalos para misturas asfálticas brasileiras foge do escopo do presente trabalho, o qual visa contribuir para a discussão e busca por métodos simples e racionais, validados nacionalmente, que auxiliem a prática da engenharia rodoviária no Brasil, sobretudo quanto a redução dos custos de manutenção e reabilitação de revestimentos asfálticos.

\section{REFERÊNCIAS}

Ahlrich, R. C. (1996) Influence of Aggregate Properties on Performance of Heavy-Duty Hot-Mix Asphalt Pavements. Transportation Research Record: Journal of the Transportation Research Board. V. 1547, p. 7-14. DOI: 10.3141/1547-02.

AASHTO M 323 (2013) Standard Specification for Superpave Volumetric Mix Design.

Cunha, M. B. (2004) Avaliação do Método de Bailey de seleção granulométrica de agregados para misturas asfálticas. Dissertação de Mestrado, Universidade de São Paulo - EESC, São Carlos, SP.

DNER ME 035 (1998) Agregados - determinação da abrasão "Los Angeles". Rio de Janeiro, RJ.

DNIT ES 031 (2006) Pavimentos flexíveis - Concreto asfáltico. Rio de Janeiro, RJ.

Ferreira, J. L. S. (2015) Melhoramento da resistência à deformação permanente de misturas asfálticas pela escolha granulométrica a partir da metodologia da faixa de agregados dominantes. Projeto de Graduação. Universidade Federal do Ceará, Fortaleza, Brasil.

Ferreira, J. L. S.; Bastos, J. S.; Soares, J. B. (2015) Validação da metodologia de faixa de agregados dominantes para avaliação e especificação da granulometria de misturas asfálticas densas. In: XXIX Congresso Nacional de Ensino e Pesquisa em Transportes, Ouro Preto - MG. Disponível em:

<www.anpet.org.br/xxixanpet/anais/documents/AC1063.pdf>. Acesso em: 14/04/2016.

Golalipour, A.; Jamshidi, E.; Niazi, Y.; Afsharikia, Z.; Khadem, M. (2012) Effect of aggregate gradation on rutting of asphalt pavements. Procedia - Social and Behavioral Sciences. V. 53, p. 440-449. DOI: 10.1016/j.sbspro.2012.09.895.

Greene, J.; Chun, S.; Choubane, B. (2014) Enhanced gradation guidelines to improve asphalt mixture performance. Transportation Research Record: Journal of the Transportation Research Board, Vol. 2456. DOI: 10.3141/2456-01.

Kim, S. (2006) Identification and assessment of the dominant aggregate size range (DASR) of asphalt mixture. Dissertation (Doctor of Philosophy). University of Florida, Gainesville. Disponível em: <http://purl.fcla.edu/fcla/etd/UFE0013464>. Acesso em: 14/04/2016. 
Mendes, L. O. (2011) Utilização do Método Bailey para a seleção de agregados em dosagem de misturas asfálticas. Dissertação de Mestrado. Universidade Federal de Juiz de Fora, MG.

Nascimento, L. A. H. (2008) Nova abordagem da dosagem de misturas asfálticas densas com uso do compactador giratório e foco na deformação permanente. Dissertação de Mestrado. Universidade Federal do Rio de Janeiro. Rio de Janeiro, RJ. Disponível em:

<http://www.coc.ufrj.br/index.php/component/docman/doc_dow nload/1476-luis-alberto-herrmann-do-nascimentomestrado?Itemid>. Acesso em: 14/04/2016.

Roberts, F. L.; Kandhal, P. S.; Brown, E. R.; Lee, D. Y.; Kennedy, T. W. (1996) Hot mix asphalt materials, mixture, design and construction. Maryland, Napa Education Foundation. ISBN-13: 978-0914313014.

Stakston, A. D. e H. Bahia (2003) The effect of fine aggregate angularity, asphalt content and performance graded asphalts on hot mix asphalt performance. WisDOT Highway Research Study 0092-45-98. Disponível em: <

minds.wisconsin.edu/handle/1793/6859>. Acesso em: $14 / 04 / 2016$

Vavrik, W. R. (2000) Asphalt mixture design concepts to develop aggregate interlock. Dissertation (Doctor of Philosophy). University of Illinois. Disponível em: < https://www.ideals.illinois.edu/.../vavrik_william.pdf >. Acesso em: 14/04/2016.

Vavrik, W. R.; G. Huber; G. Lope e W. Pine (2002) Bailey method for gradation selection in HMA mixture design. Transportation Research Board: Transportation Research Circular Nº-C044. Disponível em: < onlinepubs.trb.org/onlinepubs/circulars/ec044.pdf >. Acesso em: $14 / 04 / 2016$

White, T.; J. Stiady e A. Hand (2002) Quantifying contributions of aggregate characteristics using PURWheel laboratory tracking device. In: Aggregate contribution to hot-mix asphalt performance - ASTM STP 1412, p.1-15. DOI: $10.1520 / \mathrm{STP} 10796 \mathrm{~S}$.

Witczak, M. W.; K. Kaloush; T. Pellinen (2002) Simple performance test for superpave mix design. National Cooperative Highway Research Program, NCHRP Report 465. 